\title{
Método rápido de obtención de aceite de oliva virgen para determinación de acidez
}

\author{
Por F. Martínez (1), M. ${ }^{a}$ J. Moyano (1), J. Alba (1), M. ${ }^{a}$ A. Ruiz (1), F. Hidalgo (1) y F.J. Heredia (2) \\ (1) Almazara Experimental. Instituto de la Grasa (CSIC). \\ Avda. Padre García Tejero, 4. 41012 Sevilla, España. \\ (2) Area de Nutrición y Bromatología. Facultad de Farmacia. Universidad de Sevilla. \\ C/. P. García González, s/n. 41012 Sevilla, España.
}

\section{RESUMEN}

Método rápido de obtención de aceite de oliva virgen para determinación de acidez.

Se propone un método rápido y sencillo para obtener, a partir de muestras de aceitunas, suficiente cantidad de aceite para determinar su grado de acidez. A partir de muestras de pasta de aceitunas molidas se separan distintas fracciones que se someten a un proceso de centrifugación a 4500 r.p.m. durante 5 minutos. Se comparan los resultados de acidez de los aceites obtenidos de las muestras con adición de microtalco natural y sulfato sódico anhidro, con muestras testigo, así como con el procedimiento de extracción Abencor. Se analiza también la correlación entre la acidez de muestras de aceite obtenidas por el método Abencor, con otras obtenidas por el método normalizado en España, norma UNE 55070, basado en la extracción del aceite por el método Soxhlet. Los resultados ponen de manifiesto que en las muestras centrifugadas se obtiene cantidad suficiente de aceite para la determinación del grado de acidez, que el tratamiento con sulfato sódico anhidro consigue mayor porcentaje de recuperación, y que, en los tres casos, la acidez presenta buena correlación con la del sistema Abencor, duplicando el número de muestras analizadas respecto a este método. Así mismo, se demuestra que el valor de acidez obtenido al aplicar la norma UNE 55070 es aproximadamente 0,3 grados por encima del obtenido por el sistema Abencor.

PALABRAS-CLAVE: Aceite de oliva virgen - Acidez - Análisis Calidad - Centrifugación.

\section{SUMMARY}

Rapid method to obtain virgin olive oil for acidity determination.

A rapid and simple method to obtain, from olive samples, enough quantity of oil to determine acidity grade is proposed. From paste samples of milled olives, different fraction are separated to be centrifugated during 5 minutes at 4500 r.p.m. Oil acidity results obtained from sodium sulfate anhidrous and natural microtalc added samples are compared with blank samples, and with those obtained by the Abencor extraction procedure. The correlation between the acidity of oil samples obtained by the Abencor method is also analyzed against other samples obtained by the normalized method in Spain, norm UNE 55070, Soxhlet system. Results show that in all the centrifugated samples enough amount of oil is obtained to determin the acidity grade, it also show that treatment with sodium sulfate anhidrous obtains a bigger recovery percentage, and that in all 3 cases, the acidity shows a good correlation with that of the Abencor system, doubling the number of samples analysed by the Abencor system. It also shows that the acidity grade obtained by using the UNE 55070 norm is aproximately 0,3 grades above that obtained by the Abencor system.

KEY-WORDS: Acidity - Analysis - Centrifugation - Quality Virgin olive oil.

\section{INTRODUCCIÓN}

Los dos parámetros fundamentales que interesan al agricultor, referidos a su cosecha anual de aceitunas, son el nivel de producción y el contenido en aceite.

El nivel de producción o volumen de cosecha depende de factores como la variedad, tipo de suelo, condiciones climatológicas, riego, fertilización, tratamientos, plagas y enfermedades, etc., así como de la vecería que presenta el olivo con la producción de cosechas muy variables, normalmente alternantes en dos años consecutivos, que viene determinada principalmente por la inhibición de la inducción floral por los frutos en desarrollo (Rallo, 1998).

El contenido en aceite, que se utiliza como parámetro de valoración de las aceitunas, depende fundamentalmente de la variedad y del grado de maduración en el momento de la recolección (Civantos et al., 1992). Para su determinación se utilizan diversos métodos analíticos, que proporcionan datos de contenidos totales o parciales de aceite en la aceituna pero no de la cantidad real de aceite que se va a obtener en el proceso de elaboración, es decir, el rendimiento industrial.

Este rendimiento se calcula por una estimación, a partir de la información que proporcionan diferentes métodos analíticos de contenido en aceite, corregida por un factor variable en función de la humedad, porcentaje de materia seca y desengrasada, extractabilidad, contenido de aceite en el orujo, etc.

Hasta hace unos años, al agricultor se le pagaba exclusivamente en función del peso de aceitunas que llevaba a la almazara. Actualmente, y sobre todo en régimen de cooperativa, el pago se realiza en función del rendimiento en aceite, calculado a partir 
de los datos obtenidos del análisis de una muestra de aceitunas representativa de cada partida.

Por otro lado, el sector está realizando un gran esfuerzo para conseguir mejorar la calidad del aceite de oliva virgen. En este sentido se están produciendo modificaciones en el proceso de recepción de aceitunas y organización del patio, transformación de instalaciones con sistemas de prensas por otras con sistemas continuos de centrifugación (Alba et al., 1993; Alba, 1995; Uceda et al., 1995; Di Giovacchino, 1996), ampliación de la capacidad de trabajo para evitar el atrojado de aceitunas (Boskou, 1996; García et al., 1996), clasificación de aceites, respeto medioambiental (Alba et al., 1992; 1994). Cada vez más, se está imponiendo que los agricultores separen la aceituna procedente del árbol de la que, por determinadas circunstancias, ha caído al suelo, produciendo en el aceite características desagradables debidas a procesos fermentativos que afectan tanto a los índices químicos de calidad, fundamentalmente acidez (Hermoso et al., 1991), como a las características organolépticas, produciendo olores $y$ sabores a "suelo», «moho», «humedad», «tierra», etc. (Alba et al., 1997; Civantos et al., 1992).

Estos cambios son, en gran medida, consecuencia de una concienciación general de todo el sector olivarero para conseguir aceites de mejor calidad, que deben tener mejor comercialización, entendiendo que existirán diferencias de precio importantes entre éstos y los de peor calidad.

En este sentido, en muchas almazaras se realiza el análisis de acidez del aceite obtenido de las aceitunas, parámetro de calidad indicativo del grado de alteración hidrolítica, pagando en estos casos no sólo por cantidad de aceite, sino también por la calidad del mismo.

El método normalizado en España para determinar el grado de acidez del aceite contenido en la aceituna, se recoge en la norma UNE 55070, según la cual la extracción del aceite debe realizarse mediante el sistema Soxhlet (norma UNE 55030), y aplicando la metodología y reactivos descritos en la norma UNE 55011.

Sin embargo, para el caso de aceite de oliva virgen, que es el obtenido únicamente por procedimientos mecánicos, en condiciones térmicas que no impliquen su alteración, el actual método para acidez presenta, entre otros, el inconveniente de que la extracción con disolvente mediante el calentamiento en placa, y posterior desolventización en estufa a $105^{\circ} \mathrm{C}$, podría afectar en cierta medida el resultado.

A nivel de laboratorio, la extracción de aceite de oliva virgen se realiza por el sistema Abencor (Martínez et al., 1975), que permite observar el comportamiento de las pastas durante el proceso y proporciona un dato del contenido en aceite parcial de la aceituna. El inconveniente qué presenta es el reducido número de muestras que se pueden proce- sar: 6 por persona y hora de trabajo sin determinar la acidez, ó 12 muestras por 3 personas y hora, determinando la acidez (Martínez et al., 1975), que en ocasiones no se adapta a las necesidades del laboratorio de una almazara industrial.

En el presente trabajo se estudia la diferencia entre los valores de acidez según el método normalizado (Soxhlet), y los procedentes de aceites obtenidos por el sistema Abencor, tomado como referencia. Así mismo, se ha desarrollado un método basado en la centrifugación de una pequeña cantidad de pasta de aceitunas molidas, cuyos resultados también se comparan con los del sistema Abencor.

Debido a que en ensayos previos se comprobó que, parte del agua de vegetación separada en el proceso de centrifugación, interfería en el desarrollo del análisis, según el procedimiento propuesto, se ha ensayado el efecto producido en la separación de fases, por la adición de un deshidratante, en este caso, sulfato sódico anhidro.

Por otro lado, y teniendo en cuenta el extendido uso del microtalco natural como favorecedor de la extracción en el proceso de obtención de aceite de oliva virgen y su probada eficacia en la separación de fases, tanto a nivel industrial como de laboratorio (Alba et al., 1982), se decidió también ensayar el efecto producido por la adición de este coadyuvante tecnológico.

\section{PARTE EXPERIMENTAL}

\section{Materiales y métodos}

\section{Muestras}

Se han utilizado 50 muestras de aceitunas con un grado de maduración medio-alto, tomadas al azar, de distintas variedades, procedentes de las provincias de Jaén, Córdoba y Sevilla. De ellas, 25 muestras se han utilizado para el estudio comparativo entre el sistema Abencor y el método de centrifugación, y otras 25, para la comparación entre los métodos Abencor y Soxhlet.

Aproximadamente $3 \mathrm{Kg}$ de cada una de las muestras se trituran en un molino de martillos. La pasta de aceitunas molidas se homogeniza y se toman, siempre por triplicado, $600 \mathrm{~g}$ para la determinación del contenido en aceite parcial, según el sistema Abencor y aproximadamente $50 \mathrm{~g}$ para las determinaciones de humedad y contenido en aceite sobre seco. Del resto de pasta se toman, también por triplicado, fracciones de $50 \mathrm{~g}$ para los distintos casos ensayados en este estudio.

Para comparar el grado de acidez de las muestras de aceite obtenidas por los métodos Abencor y Soxhlet, se procede de la misma forma, es decir, a partir de la pasta inicial se toman tres fracciones de 
$600 \mathrm{~g}$ y otras tres de $50 \mathrm{~g}$ respectivamente, sometiéndose a los correspondientes sistemas de extracción.

Humedad (Norma UNE 55020): A partir de una determinada cantidad de pasta de aceitunas molidas, secando en estufa de aire a $105^{\circ} \mathrm{C}$, y expresando el resultado como porcentaje de agua.

Métodos de extracción de aceite:

Abencor: Utilizando el analizador de rendimientos Abencor $($ (Martínez et al., 1975). Este sistema reproduce el proceso de trabajo de una almazara industrial de aceitunas a pequeña escala, con el que se obtiene una muestra de aceite con todo su flavor, que puede utilizarse para valorar sus características organolépticas $u$ otras determinaciones analíticas. Las muestras de aceitunas se trituran en un molino de martillos obteniéndose una pasta que es homogeneizada inmediatamente; de cada lote se toman $600 \mathrm{~g}$. que se someten a un proceso de batido y posterior centrifugación a 3500 r.p.m., donde se obtiene el aceite, que es recogido, junto con el agua de vegetación, en una probeta graduada de $500 \mathrm{ml}$. Una vez decantado se evalúa, por lectura en la probeta, la cantidad total de aceite obtenido, que representa el "contenido en aceite parcial sobre húmedo" (C.A.H.), expresado como porcentaje.

Soxhlet: Según el método oficial, Norma UNE 55030. Las muestras previamente secadas en estufa de aire a $105^{\circ} \mathrm{C}$ se extraen con hexano, en un extractor soxhlet, durante un mínimo de 5 h, obteniéndose el "contenido de aceite total sobre seco" (C.A.S.), expresado como porcentaje.

Centrifugación: Se introducen $50 \mathrm{~g}$ de pasta de aceitunas molidas, de cada una de las muestras, en tubos de plástico translúcidos de $50 \mathrm{ml}$, que se colocan en una centrífuga MSE SUPER MINOR, con capacidad para 4 vasos. Las muestras se centrifugan durante cinco minutos a 4500 r.p.m. Para los ensayos con sulfato sódico y talco, la dosis empleada fue, en ambos casos, de $2 \mathrm{~g}$ ( $4 \%$ en peso), que se adicionaron, una vez pesada la masa en el tubo, sobre su superficie.

Transcurrido el tiempo correspondiente, se produce la separación de fases, quedando el aceite en la parte superior, por debajo de éste, una zona constituida por el agua de vegetación de la aceituna, que en el caso de las muestras tratadas con sulfato sódico es muy reducida e incluso nula, y por último, los sólidos ocupando el mayor volumen.

Acidez libre en el aceite contenido en la aceituna: Según la norma UNE 55070. A partir de la muestra de aceituna se extrae el aceite siguiendo la norma UNE 55030, determinándose el grado de acidez según el procedimiento establecido en la norma UNE 55011.

Grado de acidez: Según el método oficial en España, norma UNE 55011. Los valores de acidez, expresados como porcentaje de ácido oleico, se determinan por valoración con $\mathrm{KOH} 0.1 \mathrm{~N}$ de un de- terminado peso de aceite $(2-20 \mathrm{~g})$, en una mezcla de disolventes previamente neutralizada (alcohol-éter 1:1) y fenolftaleína como indicador.

Tratamiento estadístico de los resultados: $\mathrm{EI}$ análisis de la varianza se ha realizado utilizando el programa Statistica $\otimes$ (StatSoft, 1995).

\section{RESULTADOS Y DISCUSIÓN}

En la Tabla I se muestran los valores medios, desviación estándar y rango de humedad, contenido en aceite sobre materia seca y extractabilidad (relación entre el contenido en aceite parcial y el contenido en aceite total sobre materia húmeda). Puede observarse un alto grado de extractabilidad en todas las muestras debido, fundamentalmente, al bajo contenido en humedad. En otros casos, las denominadas "pastas difíciles", características de determinadas variedades con alto contenido en agua, tienden a presentar emulsiones en el proceso de elaboración, impidiendo su correcto agotamiento, incluso con la adición de coadyuvantes tecnológicos como el microtalco natural o enzimas (Alba et al., 1982).

Tabla I

Características analíticas de las muestras de aceitunas

\begin{tabular}{lccc}
\hline & Media & Desviación estándar & Rango \\
\hline Humedad (\%) & 41.58 & 2.66 & $34.25-46.47$ \\
C.A.S. ${ }^{*}(\%)$ & 43.68 & 3.64 & $36.70-48.78$ \\
Extractabilidad (\%) & 88.15 & 4.67 & $78.95-97.74$ \\
\hline
\end{tabular}

* C.A.S.: Contenido en aceite referido a materia seca.

\section{Rendimiento}

La eficacia del método propuesto depende en gran medida de la obtención de una cantidad de aceite suficiente para la determinación de acidez. En la Tabla II se recogen los valores medios, desviación estándar y rango relativos a la cantidad y porcentaje de recuperación obtenidos con este método, tanto para las muestras testigo como para las tratadas con microtalco y sulfato sódico.

Se aplicó un análisis simple de la varianza (ANOVA) para muestras dependientes entre porcentajes de recuperación de aceite. Los resultados indican que no existen diferencias significativas $(p<0,05)$ entre las muestras tratadas con talco y las testigo. Sin embargo, sí hay diferencia significativa $(p<0,05)$ para las muestras tratadas con sulfato sódico respecto tanto a las muestras sin tratamiento como a las tratadas con talco. 
Tabla II

Aceite recuperado por centrifugación (*)

\begin{tabular}{lcccc}
\hline & & Media & Desviación estándar & Rango \\
\hline \multirow{2}{*}{ TESTIGO } & Gramos & 4.49 & 1.14 & $2.00-6.82$ \\
& $\%$ & $8.98^{\mathrm{a}}$ & 2.29 & $3.99-13.64$ \\
\multirow{2}{*}{ MICROTALCO } & Gramos & 4.35 & 1.15 & $2.06-6.60$ \\
& $\%$ & $8.70^{\mathrm{a}}$ & 2.29 & $4.12-13.20$ \\
\multirow{2}{*}{ SULFATO } & Gramos & 5.36 & 1.26 & $2.30-8.04$ \\
& $\%$ & $10.73^{\mathrm{b}}$ & 2.52 & $4.60-16.08$ \\
\hline
\end{tabular}

$\left.{ }^{*}\right)$ Diferentes superindices indican diferencias significativas $(p<0.05)$.

La mayor cantidad de aceite recuperado se obtiene a partir de las muestras tratadas con sulfato sódico. Este incremento se debe, fundamentalmente, al efecto absorbente del $\mathrm{Na}_{2} \mathrm{SO}_{4}$ sobre el agua de vegetación de la aceituna, que consigue que los aceites así obtenidos aparezcan con un aspecto limpio, separándose fácilmente de la fase sólida (que incluye el sulfato) con el agua, mientras que, en algunas muestras testigo y la mayoría de las tratadas con tal$\mathrm{co}$, queda una determinada cantidad de agua entre la fase oleosa y la fracción sólida, que impide la total recuperación del aceite separado.

\section{Acidez}

En la Tabla III se exponen los valores medios, desviación estándar y rango de la acidez de los aceites obtenidos por los distintos tratamientos con centrifugación y por el sistema Abencor.

Tabla III

Grado de acidez (\%) de los aceites obtenidos por el sistema de centrifugación y método Abencor $\left({ }^{*}\right)$

\begin{tabular}{ccccc}
\hline & & Media & Desviación estándar & Rango \\
\hline \multirow{4}{*}{$\begin{array}{c}\text { Acidez } \\
\text { (CENTRIFUGACIÓN) }\end{array}$} & Testigo & $0.59^{\mathrm{ab}}$ & 0.30 & $0.25-1.38$ \\
\cline { 2 - 5 } & Talco & $0.57^{\mathrm{b}}$ & 0.30 & $0.26-1.38$ \\
\cline { 2 - 5 } & Sulfato & $0.60^{\mathrm{a}}$ & 0.32 & $0.25-1.45$ \\
\hline $\begin{array}{c}\text { Acidez } \\
\text { (ABENCOR) }\end{array}$ & & $0.46^{\mathrm{c}}$ & 0.33 & $0.18-1.61$ \\
\hline
\end{tabular}

$\left(^{\star}\right)$ Diferentes superíndices indican diferencias significativas $(p<0.05)$.

Un ANOVA para muestras dependientes indica que existe diferencia significativa $(p<0,05)$ entre la acidez por el método de centrifugación y la del método Abencor. Con los distintos tratamientos por centrifugación, sólo se encuentra diferencia significativa $(p<0,05)$ entre los aceites obtenidos con talco y los obtenidos con sulfato.
Tabla IV

Ecuaciones de regresión para la acidez obtenida por el método Abencor respecto de las obtenidas por el sistema de centrifugación

\begin{tabular}{|c|c|}
\hline Ecuación & $r^{*}$ \\
\hline $\begin{array}{l}\text { Acidez (ABENCOR) }=-0.1745+1.0741 \\
{ }^{*} \text { Acidez (TESTIGO CENTRIFUGACIÓN) }\end{array}$ & $0.95544(p<0.05)$ \\
\hline $\begin{array}{c}\text { Acidez (ABENCOR) }=-0.1368+1.0464 \\
{ }^{*} \text { Acidez (TALCO CENTRIFUGACIÓN) }\end{array}$ & $0.95172(p<0.05)$ \\
\hline $\begin{array}{c}\text { Acidez (ABENCOR) }=-0.1346+0.9977 \\
{ }^{*} \text { Acidez (SULFATO CENTRIFUGACIÓN) }\end{array}$ & $0.94730(p<0.05)$ \\
\hline
\end{tabular}

En la Tabla IV se presentan las ecuaciones de regresión lineal entre el grado de acidez de los aceites obtenidos por el sistema Abencor, tomado como referencia, respecto de los valores por los distintos tratamientos en centrifugación. Los elevados coeficientes de correlación $\left(r^{\star}>0,95\right)$ permiten calcular dicha acidez con suficiente fiabilidad en todos los casos.

Tabla V

Grado de acidez (\%) de los aceites obtenidos por los sistemas Abencor y Soxhlet (*)

\begin{tabular}{lccc}
\hline & Media & Desviación estándar & Rango \\
\hline Acidez (ABENCOR) & $0.44^{\mathrm{a}}$ & 0.20 & $0.19-1.13$ \\
Acidez (SOXHLET) & $0.78^{\mathrm{b}}$ & 0.27 & $0.51-1.57$ \\
\hline
\end{tabular}

$\left({ }^{*}\right)$ Diferentes superíndices indican diferencias significativas $(p<0.05)$.

En la Tabla $V$ se ofrecen los valores medios, desviación estándar y rango de la acidez para los aceites obtenidos por los métodos Abencor y Soxhlet. Como cabía esperar, la acidez según el método Soxhlet presenta valores superiores $(0,34$ grados por término medio) réspecto a los obtenidos con el método Abencor, existiendo diferencia significativa $(p<0,05)$ entre ambos. Este resultado se debe, sin duda, al calentamiento a que se somete el aceite durante un período prolongado de tiempo, en la extracción con el sistema Soxhlet. No obstante, es posible calcular la acidez Abencor con la suficiente fiabilidad $\left(r^{*}=0.9528, p<0,05\right)$ mediante la ecuación de regresión correspondiente:

Acidez $($ ABENCOR $)=-0,1153+0,7136 *$ Acidez $($ SOXHLET $)$

\section{CONCLUSIONES}

A la vista de los resultados obtenidos se puede concluir que:

- En muestras con elevado grado de extractabilidad, la centrifugación de 50 gramos de pasta 
de aceitunas produce cantidad de aceite suficiente para la determinación de acidez según la norma UNE 55011.

- El mayor porcentaje de recuperación de aceite, de las muestras obtenidas por centrifugación, se consigue con el tratamiento con sulfato sódico anhidro.

- En todos los casos existe una buena correlación entre el grado de acidez de las muestras obtenidas por centrifugación y el sistema Abencor, pudiéndose calcular el dato obtenido por este último, a partir de las correspondientes ecuaciones de correlación. Generalizando, se puede considerar que los aceites obtenidos por centrifugación, presentan aproximadamente 0,1 grado de acidez por encima de los obtenidos en Abencor.

- Para el caso de laboratorios de control de aceitunas que utilicen, para obtener el rendimiento industrial, sistemas analíticos de contenido en aceite total, se propone el método de centrifugación para determinar, cuando sea necesario, el grado de acidez, ya que con él se pueden procesar al menos, el doble de muestras que con el sistema Abencor.

- La acidez de los aceites obtenidos siguiendo la norma UNE 55070 presenta diferencia significativa $(p<0,05)$ con la del aceite original contenido en la aceituna, considerando como tal el que se obtiene con el sistema Abencor. El valor según el método Soxhlet es aproximadamente 0,3 grados superior al del método Abencor, existiendo una alta correlación entre ambos.

\section{AGRADECIMIENTOS}

Los autores expresan su gratitud y reconocimiento a M. de la Fuente, M. ${ }^{a}$ C. Díez-Astrain, J. Navarro, E. Liñán y A. Camas, por su eficaz colaboración durante el desarrollo de los ensayos.

\section{BIBLIOGRAFÍA}

Aenor, Asociación Española de Normalización y Certificación. (1964).--Norma UNE 55011; Madrid. Aenor, Asociación Española de Normalización y Certificación. (1973).-Norma UNE 55-020-73; Madrid.

Aenor, Asociación Española de Normalización y Certificación. (1961).--Norma UNE 55030; Madrid.
Aenor, Asociación Española de Normalización y Certificación. (1964).--Norma UNE 55070; Madrid, 1964.

Alba, J. (1995).—«El orujo de aceituna. Evolución, estado actual y perspectivas".-Agricultura, 64, 84-86.

Alba, J., Hidalgo, F., Martínez, F., Ruiz, M. ${ }^{a}$ A., Moyano, M. J. (1993).— «Procesos de elaboración: Nuevas técnicas de extracción».-Expoliva'93. Dossier Oleo, 2, 40-59.

Alba, J., Hidalgo, F., Martínez, F., Ruiz, M. ${ }^{a}$ A., Moyano, M. ${ }^{a}$ J. (1994).- «Impacto ecológico y ambiental originado por el nuevo proceso de elaboración de aceite de oliva".- III Fórum Internacional del Aceite SIO'94. Reus.

Alba, J., Izquierdo, J.R., Gutiérrez, F. (1997).—«Aceite de oliva virgen. Análisis sensorial».-Editorial Agrícola Española S.A. Madrid, España

Alba, J., Muñoz, E., Martínez, J.M. (1982).— -Obtención del aceite de oliva: empleo de productos que facilitan su extracción».-Alimentaria, 138, 25-55.

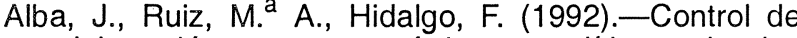
elaboración y características analíticas de los productos obtenidos en una línea continua ecológica.Seminario Internacional de Montoro. Dossier Oleo, 2, 43-48.

Boskou, D. (1996). - «Olive Oil. Chemistry and Tecnology».AOCS Press: USA.

Civantos, L., Contreras, R., Grana, R. (1992).— «Obtención del aceite de oliva virgen».-Editorial Agrícola Española, S.A. Madrid, España.

Di Giovacchino, L. (1996). - «Influencia de los sistemas de extracción en la calidad del aceite de oliva".-Olivae, $63,52-63$

García, J.M., Gutiérrez, R., Castellano, J.M., Perdiguero, S., Morilla, A., Albi, M.A. (1996).- - Influence of storage temperature on fruit ripening and olive oil quality". Journal of Agricultural and Food Chemistry, 44, 264-267.

Hermoso, M., Uceda, M., García-Ortiz, A., Morales, J., Frías, L., Fernández, A. (1991).—-Elaboración de aceite de oliva de calidad». Dirección General de Investigación, Tecnología y Formación Agroalimentaria y Pesquera. Consejería de Agricultura y Pesca. Junta de Andalucia. Sevilla.

Martínez Suárez, J.M., Muñoz Aranda, E., Alba Mendoza J., Lanzón Rey, A. (1975).— «Informe sobre utilización del analizador de rendimientos "Abencor" ".-Grasas y Aceites, 26 (6), 379-385

Rallo, L. (1998).- «Fructificación y Producción, en E Cultivo del Olivo». 2. ${ }^{a}$ Ed. (Barranco, D., FernándezEscobar, R., Rallo, L., Eds.).-Ediciones MundiPrensa.

StatSoft, Inc. (1995).- «STATISTICA for Windows».StatSoft, Inc; Tulsa, OK.

Uceda, M., Hermoso, M., González J. (1995).— - «volución de la tecnología de extracción del aceite de oliva". Alimentación, Equipos y Tecnología.Abril, 75-80. 